\title{
Eixos conceituais da política exterior do Brasil
}

\section{AMADO LUIZ CERVO*}

A elaboração do pensamento político aplicado à conduta exterior do Brasil se faz por pessoas individualmente ou em contexto de vinculação a órgãos ou instituições diversos. Os conceitos provêm, pois, de múltiplas origens. O discurso diplomático e as mensagens presidenciais correspondem a seus nichos genéticos privilegiados. Mas esses conceitos são também localizados em outros textos, tais como os pronunciamentos de delegados brasileiros em organismos internacionais (ONU, UNCTAD, Conferências diversas, do Desarmamento, do Meio Ambiente, dos Direitos Humanos, dos Direitos do Mar, da População, da Mulher etc.), os comunicados conjuntos expedidos ao termo de visitas oficiais de altas autoridades estrangeiras, o debate parlamentar. Lideranças políticas e sociais como também intelectuais e acadêmicos agregam por sua vez idéias próprias à política exterior do país.

Em seus quarenta anos de existência, a Revista Brasileira de Política Internacional (RBPI) espelha essa riqueza conceitual que escande o pensamento brasileiro acerca da política exterior. É raro, convém observar, o leitor encontrar textos conceituais em estado puro, mesmo porque em diplomacia convém freqüentemente ocultar idéias e intenções. Mas o pensamento está lá, variado e rico, complexo e concêntrico, diluído na matéria. Isolá-lo — o que buscamos nessas páginas - exige destilá-la. Duas fases, entretanto, são claramente distintas no que se refere à natureza dos textos encontrados na RBPI: a fase do Rio de Janeiro, entre 1958 e 1992, quando a Revista se voltava sobretudo para a publicação de discursos e documentos oficiais provindos da Chancelaria, mas também da Presidência e do Congresso Nacional, e a fase de Brasília, desde 1993, em que ela transformou-se em uma revista de análise da política exterior e das relações internacionais. Essa modificação editorial convinha por duas razões: por um lado, as publicações seriadas do Itamarati passam a oferecer ao público os documentos oficiais indispensáveis para acompanhar as posições externas do Brasil; por outro, a expansão dos estudos de relações internacionais no país exige uma revista de análise que interprete o movimento da diplomacia.

Para quem esteja um pouco familiarizado com a história, a busca dos conceitos chaves da política exterior do Brasil na RPBI corresponderia a um teste, 
a um exercício de comprovação de hipóteses, como se diz na Academia. Perguntamos à RBPI se ela nos esclarece sobre as seguintes questões:

1) Como ocorreu a introspecção da política exterior, que se destinou crescentemente a preencher requisitos de desenvolvimento nacional?

2) Que lógica estabeleceu-se entre a política desenvolvimentista e a política brasileira de comércio exterior, de desarmamento, a política nuclear, a atitude diante da Guerra Fria, o acoplamento ao diálogo Norte-Sul, a aproximação ao Terceiro Mundo?

3) Existiu uma formulação teórica em torno do pragmatismo com o fim de apurá-lo ao ponto de multiplicar os meios com que realizar objetivos externos?

4) As relações especiais com os Estados Unidos foram de fato sacrificadas em favor da condição ideal de global trader e da estratégia de diversificação de parcerias?

5) O conceito de segurança modificou-se, transitando da segurança coletiva ao abrigo da potência hegemônica da área para o da segurança nacional, assentada em meios próprios?

6) Perceberam-se distorções de efeitos na política exterior, tais como a incongruência entre um universalismo apregoado e uma introspeção isolacionista, entre a reivindicação e a disponibilidade de poder?

7) Por fim, de que forma a instabilidade política, a coerção do regime militar em particular, condicionou a manifestação do pensamento? Exerceram, por outro lado, os editores que tiveram por longo tempo a Revista em suas mãos (José Honório Rodrigues e Cleantho de Paiva Leite) algum controle sobre o conteúdo da mesma?

Examinaremos de forma um tanto dispersiva os textos da Revista, mas procurando referi-los a essas e a outras questões relevantes para o pensamento nacional acerca das relações exteriores do país nesses últimos quarenta anos, buscando assim dar-lhe coerência genética por meio da identificação e da evolução de seus eixos conceituais.

\section{Desarmamento, universalismo e integração}

Três idéias emergem em 1958, ano do lançamento da Revista, como subsídios teóricos ao pensamento diplomático brasileiro. Gonzalo J. Fácio advogava o desarmamento dos países latino-americanos, apoiado na presunção de que economias de recursos destinados às forças armadas favoreceriam o desenvolvimento regional ("O desarmamento como fator de desenvolvimento econômico na América Latina”, 1(2): 28-44, jun. 1958). Estava longe, todavia, de vincular a idéia do desarmamento regional à do desarmamento global, que seria requisitado também em favor do desenvolvimento por Araújo Castro anos depois. 
Fácio alegrava-se com a repercussão de suas idéias na imprensa norte-americana, mesmo porque pensava em manter a segurança hemisférica sob dependência dos Estados Unidos, bastião do combate ao comunismo.

Por outro lado, a espinhosa questão do restabelecimento das relações diplomáticas com a União Soviética agitava a imprensa e a opinião nacional nesse ano de 1958. Dela ocupou-se o grande Oswaldo Aranha. Em seu entender, apesar da controvérsia e da divisão das opiniões, tanto dos meios de imprensa quanto do Governo, acerca da conveniência do restabelecimento das relações, comerciais ou diplomáticas ou ambas, era mister lembrar que em 1945, quanto isso ocorreu, a decisão foi absorvida como uma decisão natural e, quanto ao rompimento, em 1947, deu-se por mero incidente diplomático, sem pressões da opinião ou dos partidos. Aranha considerava muito natural o restabelecimento dessas relações, cuja ruptura em nada beneficiava, ao contrário debilitava a posição internacional do Brasil. O restabelecimento pleno, diplomático e comercial, convinha sob múltiplos ângulos de interesses, mas sobretudo beneficiaria a economia de um país que se industrializava a passos rápidos. As divergências ideológicas e de concepção dos regimes políticos, invocadas pelos que se opunham ao restabelecimento, eram compreensíveis, mas não deveriam impedir a boa convivência entre as nações. Tampouco deve o Brasil temer a infiltração comunista com a chegada de diplomatas russos porque não são eles a origem nem o veículo daquela infiltração. Convém, pois, ao Brasil, em razão de sua maturidade e de seu peso na comunidade internacional, manter uma política exterior aberta e universalista, desprovida de complexos e mesquinharias políticas de nações dependentes: “O Brasil deve manter relações com os países soviéticos sem temores anódinos, porque não é mais um país subdesenvolvido nem uma colônia onde os imperialismos possam disputar vantagens ou privilégios”, concluía o velho chanceler Oswaldo Aranha ("Relações diplomáticas com a União Soviética”, 1(2): 18-28, jun. 1958).

Uma terceira idéia-força aflora nos textos de 1958: a integração econômica latino-americana. No espírito da Operação Pan-Americana de Juscelino Kubitschek, o analista José Garrido Torres invoca a autoridade de antigos e novos próceres da união regional, Bolívar, Mauá, Andrés Bello, Rio Branco, Saenz Peña, Hélio Lôbo, Vargas e Roberto Campos. Os obstáculos ao mercado regional residem segundo o autor na falta de complementaridade das economias e na política restricionista dos Estados na primeira fase da industrialização. O modelo introspectivo induziu distorções estruturais: capacidade ociosa, baixa produtividade, preços elevados de consumo, inflação, bloqueio das exportações, déficit de balança comercial e de pagamentos, endividamento. Não se há de condenar o processo industrial da América Latina. Contudo, o estádio de evolução da indústria colocou-a ante o desafio de responder corretamente à necessidade sentida no momento de ampliar a dimensão do mercado, por meio de um mercado regional latino-americano "de 
caráter multilateral e competitivo, fundado na observação objetiva dos fatos, tais como ora se apresentam, e refletindo anseios generalizados, no sentido de uma ação concertada rumo à meta final da estruturação, gradual e progressiva, de uma grande área comercial”. Esta concepção geoeconômica se levada à prática política daria à América Latina condições "para promover sua prosperidade, com estabilidade até hoje desconhecida”. Torres faz em seu artigo uma avaliação exaustiva do processo latino-americano de industrialização e fundamenta sua proposta amplamente elaborada de integração econômica em princípios sábios e de bom senso que somente muito mais tarde iriam presidir a estratégia das relações regionais conduzida pelos principais Estados ("Por que um mercado regional latinoamericano?”, 1(2): 74-121, jun. 1958).

A visão dinâmica e moderna de Torres chocava-se contudo com a inércia política e social da América Latina e com a indisposição norte-americana de cooperar para seu desenvolvimento. Por isso não via sua proposta de integração econômica deslanchar, tampouco observava frutos oriundos da Operação PanAmericana. Ao proceder a um balanço dessa última, uma tentativa de integração econômica do continente, escrevia em 1960: "Assim a OPA permanece um propósito, uma expressão de sentimento, um estado de espírito, uma declaração de intenções, um convite aceito, em princípio, por todos os governos americanos para uma ação conjunta que não está planejada em termos de execução metódica, multiforme mas coordenada. Ainda não é uma política; é um diagnóstico. Aguarda um roteiro; não se lhe deu conteúdo programático. Corre o risco, portanto, de confirmar a regra das manifestações líricas em matéria de cooperação econômica no hemisfério. Poderá dissipar-se por falta de consistência” (Garrido Torres, “Operação Pan-Americana, uma política a formular”, 3(10): 33-50, jun.1960).

\section{A radicalização dos conceitos nos anos sessenta}

Abrindo-se à divergência de opinião que nos anos sessenta exacerbou-se em torno da política exterior, em 1961 a Revista abriga dois artigos que evidenciam concepções em conflito. O escritor Alceu Amoroso Lima, notável representante do pensamento conservador, lamentava a deterioração, prejudicial em seu entender, das relações entre os Estados Unidos e a América Latina. Indicava seis causas para explicar esse curso político: o nacionalismo cada vez mais forte dos latinos; a infiltração e a propaganda comunista; o sentimento antiamericano dos movimentos revolucionários; a falta de tato de diplomatas norte-americanos que lidam com os povos do sul e, enfim, os temores criados pela ação cultural das Fundações norte-americanas, como a Fundação Rockefeller e a Fundação Ford. Precisamente numa cooperação cultural ampla que sugeria, o autor encontrava o remédio para as dificuldades do tempo ("Os Estados Unidos e a América Latina”, 4(13):17-28, mar. 1961). 
Antes de sua renúncia, o Presidente Jânio Quadros redigiu um artigo para a revista norte-americana Foreign Affairs, que a RBPI reproduziu em dezembro de 1961. O texto tornou-se um clássico da literatura porquanto prenunciava o pensamento ainda não explícito de San Tiago Dantas, entre outros, que seria levado a público pela Revista, pensamento batizado de Política Externa Independente. Em seu preâmbulo, o Presidente anuncia um Brasil mais presente, uma "nova força no cenário mundial”, não militar mas como projeção de sua própria grandeza relativa entre as nações e de seu recente crescimento demográfico e industrial. Quatro idéias consignam à política exterior os parâmetros de ação segundo Quadros: a) o abandono do servilismo a interesses estrangeiros, fossem eles os mais dignos, e a busca de proteção aos verdadeiros interesses nacionais que se consubstanciam no desenvolvimento; b) a depuração do ocidentalismo ao qual se filia o Brasil de suas coerções e a aproximação aos povos atrasados da América Latina, África e Ásia com os quais o Brasil também comunga raça e civilização e pretende constituir uma frente de luta pela superação das desigualdades entre as nações; c) a inauguração de um pan-americanismo de conteúdo econômico e social, superando sua fase política e ideológica, que ainda pretende preservar o Governo dos Estados Unidos, como se observou na crise de Cuba; d) a condição de liberdade que advém do fato de o Brasil não vincular-se a nenhum bloco e de ostentar uma composição cultural e étnica plural aconselha-o a não assumir responsabilidades na Guerra Fria, a manter relações diplomáticas e comerciais com todas as nações do mundo, tanto mais que o crescimento e a diversificação da produção interna estão a exigir iniciativas em todos os quadrantes do globo (Jânio Quadros, “Nova Política Externa do Brasil”, 4(16): 150-156, dez. 1961).

As esperanças pareciam animar o pensamento político brasileiro acerca da integração regional, tão cara, como já se observou, ao articulista de 1958, José Garrido Torres. Ao proceder em 1963 a um balanço do desempenho da Associação Latino-Americana de Livre Comércio (ALALC), instituída pelo Tratado de Montevidéu em 18 de fevereiro de 1960, o embaixador Henrique Valle escreve em tom deveras otimista. Não disfarça, entretanto, a disparidade de proveito auferido pelos integrantes da Associação. Desde o início, em razão de seu avanço industrial, pensava-se no Brasil em converter a zona de livre comércio em mercado para esse segmento da produção. Convictos de que o processo de integração econômica poder-lhes-ia ser útil, os brasileiros deveriam divulgar no entender de Valle uma mentalidade alalquiana e convencer os vizinhos de que nem tudo o que serve ao desenvolvimento de um país serve necessariamente ao desenvolvimento de outro (“ALALC: realizações e perspectivas”, 6(23): 413-430, set. 1963). Essa filosofia provavelmente terá contribuído para o malogro histórico da ALALC.

Um sensível progresso no sentido da clareza dos conceitos aplicados à política exterior do Brasil adviria com o pensamento de João Augusto de Araújo Castro, feito Ministro das Relações Exteriores em 23 de agosto de 1963. Em famoso 
discurso pronunciado ante a XVIII Assembléia Geral das Nações Unidas definiu com idéias precisas a posição que o Brasil vinha delineando na Conferência de Genebra acerca do desarmamento, como ainda acerca da descolonização e do desenvolvimento econômico em organismos internacionais, particularmente no sistema ONU: "É fácil precisar o sentido de cada um dos termos desse trinômio. A luta pelo Desarmamento é a própria luta pela Paz e pela igualdade jurídica de Estados que desejam colocar-se a salvo do medo e da intimidação. A luta pelo Desenvolvimento é a própria luta pela emancipação econômica e pela justiça social. A luta pela Descolonização, em seu conceito mais amplo, é a própria luta pela emancipação política, pela liberdade e pelos direitos humanos” (João Augusto de Araújo Castro, "A posição do Brasil nas questões do desarmamento, desenvolvimento e descolonização”, 6(23): 518-535, set. 1963). Essas idéias lançariam profundas raízes no pensamento e na prática política da diplomacia brasileira, consolidando seu traço não confrontacionista e orientando-a para uma estratégia de cooperação internacional com os países avançados e de solidariedade com a frente dos povos atrasados.

Os três pensamentos progressistas da diplomacia brasileira dos anos sessenta, Araújo Castro, Afonso Arinos e San Tiago Dantas tiveram boa acolhida nas páginas da RBPI. Este último foi privilegiado com um volume inteiro, que José Honório Rodrigues publicou em 1964, não sem significar em primeiro lugar a liberdade de expressão de que gozava a Revista após a implantação do regime militar e em segundo lugar seu repúdio ao pensamento político que se projetou durante o governo de Castelo Branco. Em sua nota introdutória, o editor assim se referia ao mentor da Política Externa Independente: “A diplomacia do desenvolvimento, que sustentou com clareza invejável e convencido de sua conveniência aos interesses nacionais e aos deveres da defesa da paz, representou — embora uma continuação da iniciativa da Presidência Jânio Quadros — a consolidação elaborada da determinação de não voltar nunca mais àquela posição irreal, modesta e rotineira que o Brasil vinha mantendo após a morte do Barão do Rio Branco” (José Honório Rodrigues, “Nota Liminar”, 7(27): 377-379, set. 1964). A idéia de um projeto nacional de desenvolvimento, elaborado com autonomia e em função de percepções próprias do interesse nacional, toma corpo no pensamento diplomático com o vigor da argumentação de San Tiago Dantas. A política exterior é concebida e posta a serviço de objetivos nacionais que têm "como finalidade assegurar por todos os meios o nosso desenvolvimento econômico, o nosso progresso social...”. Ela deve, entretanto, derramar-se externamente na luta pela emancipação de todos os povos, pela erradicação dos resíduos do colonialismo. Deve outrossim tomar forma de ação em defesa do princípio de não-intervenção e de autodeterminação dos povos, que espelha externamente a essência da democracia (San Tiago Dantas, "Política exterior do Brasil, discurso de posse do Chanceler San Tiago Dantas”, 7(27): 440-445, set. 1964; ver também o artigo de Renato 
Archer, “San Thiago: Formulador da Política Externa Independente”, 27(105-108): 7-12, 1984).

A linha de pensamento autonomista sofre brusca ruptura com a ascensão dos militares e do grupo filoamericano ao poder em abril de 1964. Uma correção de rumos da diplomacia trará à ordem do dia velhos conceitos e práticas que a corrente conservadora do pensamento brasileiro continuava a advogar. Assim resumia o significado desse novo momento diplomático que se estenderia entre 1964 e 1967 o primeiro Chanceler do regime militar, Vasco Leitão da Cunha: "Em primeiro lugar, a recolocação do Brasil num quadro de relações prioritárias com o Ocidente. Isto significa defender a política tradicional de boa vizinhança na América, a segurança do Continente contra a agressão e a subversão vindas de fora ou de dentro dele; a consolidação dos laços de toda ordem com os Estados Unidos, nosso grande vizinho e amigo do norte; a ampliação de nossas relações com a Europa Ocidental e com a Comunidade Ocidental de Nações” ("Entrevista do Chanceler Vasco Leitão da Cunha sobre Política Exterior brasileira”, 7(27): 591-598, set. 1964). A diplomacia autonomista dos governos Jânio Quadros e João Goulart, concebida por homens da envergadura de pensamento político de Afonso Arinos de Melo Franco, San Tiago Dantas, Araújo Castro e Renato Archer, cederia lugar a efêmero interlúdio entre 1964 e 1967, durante o governo de Castelo Branco. A substituição de pensamento na Chancelaria comportava uma ruptura com os conceitos de projeto nacional, diplomacia universalista, luta pelo desenvolvimento e descolonização, relações com todas as nações e a projeção em seu lugar da aliança com os Estados Unidos, da segurança coletiva, do ocidentalismo, da ideologia anticomunista e do princípio intervencionista.

A “revolução” de 1964 avançara sem base objetiva em sua correção de rumos da diplomacia. Ela mesma, de dentro de si, rapidamente recuperou tendências anteriores, alicerçadas em percepções realistas dos interesses nacionais, sacrificando aquela série de conceitos abruptamente valorizados durante o primeiro governo militar. Regressava-se ao pensamento desenvolvimentista já com a ascensão de Artur da Costa e Silva à Presidência da República e de José de Magalhães Pinto à Chancelaria, em 1967.

Desde 1967, a $R P B I$ registra não só a recuperação da herança conceitual de Oswaldo Aranha, Garrido Torres, Jânio Quadros, San Tiago Dantas, Araújo Castro, Afonso Arinos entre outros formuladores de um pensamento "brasileiro" em política exterior, mas testemunha o refinamento conceitual do paradigma de política exterior desenvolvimentista. O grande debate se trava em 1967 em torno da questão nuclear, considerada então emblemática das possibilidades de desenvolvimento nacional. O chanceler José de Magalhães Pinto vê a divisão do mundo entre ricos e pobres acentuar-se e, mais grave, vê as estruturas políticas e jurídicas internacionais evoluírem no sentido de consagrar e manter essa distância. Daí nasce a disposição de resistir externamente "a todas as tentativas de 
institucionalização, sob formas jurídicas, em tratados internacionais, dessa nossa presente menoridade econômica e tecnológica" ("Discurso a cientistas brasileiros em 7 de junho de 1967”, 10(37-38): 9-11, mar.-jun. 1967.). Os novos dirigentes de 1967 têm, pois, uma visão radicalmente distinta daquela que havia triunfado em 1964 acerca das relações internacionais: o mundo é adverso, não cooperativo; as potências se guiam por interesses internos, não pela boa vontade; o jogo das forças tende a perpetuar a desigualdade e o atraso, não a promover o desenvolvimento; um país em desenvolvimento deve ter uma política realista, que comporta desconfiança diante da ordem internacional e esperteza de conduta se quiser auferir algum ganho com sua política exterior.

Em Conferência pronunciada na Escola Superior de Guerra, a 28 de junho de 1967, o Chanceler Magalhães Pinto estabelece os fundamentos e define os parâmetros da política exterior do Brasil, expressando a nova inflexão conceitual em curso.

Partindo da premissa de que a violência é apanágio das sociedades que sofrem privações, o novo Governo estabelecerá um vínculo lógico entre a prosperidade e a estabilidade política, particularmente da democracia. A segurança, segundo a mesma lógica, é concebida como variável dependente do desenvolvimento. As nações pobres são o fermento onde germinam a instabilidade política e a violência, daí a necessária propensão à promoção do desenvolvimento nacional, tanto mediante as diretrizes da política interna quanto externa. No mundo subdesenvolvido, contudo, o progresso depende de uma ação internacional solidária, vertical e horizontal: "Na cooperação para o desenvolvimento vê o Governo brasileiro um caminho para a superação dessa dramática divisão do mundo no sentido norte-sul, entre povos ricos e pobres”, afirma o Chanceler. Após observar o arrefecimento da Guerra Fria entre os países desenvolvidos, portanto da tensão militar e ideológica em âmbito global, bem como o aparecimento de novos centros de poder como fruto do desenvolvimento econômico, o Governo reivindica como parte da soberania nacional e responsabilidade das forças armadas sobre a segurança do país, por modo a desvinculá-la da dependência externa de hegemonias ou sistemas de aliança. Mas, sem os meios fornecidos pelo desenvolvimento econômico, essa responsabilidade não pode ser exercida. Tampouco terá solução definitiva se a penúria continuar alimentando conflitos sociais no interior da própria nação: "Essa a razão da ênfase que venho dando no Ministério das Relações Exteriores aos problemas do desenvolvimento" (Magalhães Pinto, "Fundamentos da política exterior do Brasil; Conferencia pronunciada na Escola Superior de Guerra, em 28 de junho de 1967”, 10(37-38): 11-17, mar.-jun. 1967). Na prática, essa filosofia política define a ação da diplomacia: dar ênfase à cooperação para o desenvolvimento nos órgãos regionais e universais, apoiar a reforma das bases do comércio internacional, aproveitar sistematicamente todas as formas de intercâmbio bilateral, estimular a captação de recursos e tecnologias, promover a nuclearização 
pacífica do país. Não se trata de realizar interesses unilaterais, mas de harmonizar interesses internacionais, numa visão generosa e dinâmica das relações entre os povos.

Os tratados nucleares de Não Proliferação (TNP) e de proscrição de armas atômicas na América Latina (Tlatelolco) eram negociados quase simultaneamente em 1967. Em ambos os casos, a diplomacia brasileira movimentou-se com grande empenho para passar aos textos suas idéias: eliminar as limitações ao acesso à tecnologia nuclear, considerada indispensável ao desenvolvimento, que as potências nucleares impunham às outras quando aderissem ao TNP; criar uma zona livre de armas nucleares na América Latina; obter o quanto possível a redução das experiências e um progressivo desarmamento nuclear mundial. As emendas que o Brasil propôs quando da negociação do TNP não foram aceitas, motivo porque o país negou-se à adesão. Mas o Tratado do México estabeleceu claramente a diferença entre os dois usos possíveis da tecnologia nuclear e o país firmou-o. Davam-se assim passos firmes no sentido de tornar claras a política nuclear e a doutrina de desarmamento nuclear que seriam veiculadas posteriormente com coerência pela diplomacia (Sérgio Correa da Costa, "Discurso na 297ª reunião do Comitê das Dezoito Nações sobre Desarmamento, Genebra, 29 maio 1967”, 10(3738): 43-45, mar.-jun. 1967).

Um volume da Revista foi dedicado à Amazônia em 1968. De forma aberta e objetiva, os textos argumentam em favor da integridade territorial e da necessidade de a Amazônia permanecer sendo brasileira. Evidenciam a cobiça de potências estrangeiras, discutem as possibilidades de cooperação regional para o desenvolvimento, o projeto do Hudson Institute norte-americano de criação de um sistema de grandes lagos interligando as bacias hidrográficas, o acesso de estrangeiros à propriedade das terras amazônicas e a política de segurança nacional para a Amazônia. O volume era oportuno e respondia a preocupações sérias que se derramavam sobre a imprensa, o Congresso Nacional, o Itamaraty, os meios científicos e os órgãos de segurança. Com esses textos, mais uma vez, firmavamse posições diante de um desafio, o de enfrentar ameaças e manter sob controle nacional a área sobre a qual, como nos meados do século XIX, elaboravam-se no exterior projetos de ocupação (Especial: “Amazônia”, 11(41-42), mar.-jun. 1968).

\section{Comércio exterior}

Prosseguindo em seu hábito de publicar números temáticos, a Revista contempla em 1970 o comércio de produtos de base. Há vinte anos organismos internacionais vinham discutindo a questão sem alcançar resultados em favor das expectativas dos países em desenvolvimento, os grandes fornecedores de matériasprimas. Nesse número, consolida-se a conceituação brasileira das soluções pelas quais a diplomacia deveria envidar esforços para romper, conforme afirmava 
Ronaldo Costa, o círculo vicioso do subdesenvolvimento: “a industrialização interna e a mudança das regras que regulam o comércio internacional” ("Mercado internacional de produtos de base; principais linhas de ação do Brasil”, 13(5152): 7-16, set.- dez. 1970).

A política de comércio exterior alcança maior clareza conceitual nesse ano de 1970. Parte da política exterior, constitui segundo o Chanceler Mário Gibson Barbosa um dentre vários instrumentos de ação externa com que se procura carrear do exterior insumos e condições favoráveis ao processo de desenvolvimento. A divisão internacional do trabalho não permite que o princípio da liberdade de trabalho incorporado por órgãos reguladores no pós-guerra, especialmente pelo GATT, seja aplicado em sua generalidade, porquanto supõe que exista simetria entre os países. Nessa constatação fundamenta-se a reivindicação brasileira de tratamento preferencial sem contrapartida em favor dos países em desenvolvimento por parte dos avançados. E mais: a doutrina do livre comércio não é aplicada nos países desenvolvidos, que impõem restrições de natureza diversa às importações brasileiras, particularmente as de manufaturados, no momento em que o país, em razão de seu avanço industrial, transita do modelo substitutivo de importações para o substitutivo de exportações. De todo modo, ficam claras as esferas de ação da diplomacia, a necessidade de aprimorar a capacidade de negociação com o intuito de modificar as regras do comércio internacional e de transformar o comércio exterior do país em instrumento propulsor do desenvolvimento nacional ("Política brasileira de comércio exterior”, 13(49-50): 63-70, mar.-jun.1970).

A UNCTAD será o foro de cujos debates e decisões a diplomacia brasileira esperava obter os resultados de sua ação. A III UNCTAD (Santiago, abril-maio de 1972) mereceu um número temático da Revista, cujos textos trazem precisões e fazem avançar a conceituação da política de comércio exterior. Segundo Álvaro Gurgel de Alencar, seus postulados eram três: a primazia dada à criação de um grande mercado interno de consumo; para tanto, tornam-se indispensáveis os aportes externos de receitas de exportação e financiamentos; o ritmo do desenvolvimento terá que se dar sob a forma de "salto tecnológico". A necessidade de ampliar o comércio de exportação resulta da própria necessidade de aumentar a capacidade de importação de que depende o ritmo do crescimento, mas também da necessidade de manter utilizada e de ampliar a capacidade de produção, como ainda de manter em nível adequado a capacidade de endividamento externo do país e de absorção progressiva de tecnologias. Em conseqüência disso, à política de comércio exterior na esfera multilateral ficam consignados os seguintes objetivos que complementam a ação da esfera bilateral: provocar modificações na estrutura do comércio internacional, de sorte a se poder ampliar e diversificar a pauta das exportações (expansão das exportações de manufaturados), expandir o volume e melhorar as condições do financiamento internacional e, enfim, criar facilidades de acesso a tecnologias indispensáveis ao desenvolvimento econômico 
(“Reformulação das regras do comércio internacional”, 14(57-58): 19-26, jan.jun. 1972.).

A UNCTAD serviu igualmente de ocasião para incorporar ao pensamento diplomático brasileiro o conceito de multilateralismo do desenvolvimento, em referência ao multilateralismo dos países desenvolvidos. Com efeito, estes últimos congregaram-se em organismos próprios, como a OCDE e o COMECON, enquanto o GATT, criado para liberalizar o comércio internacional, tardiamente reformulouse para introduzir o conceito de desenvolvimento em sua filosofia de ação. A UNCTAD, tanto sua convocação em 1964 quanto sua institucionalização por resolução da ONU, resultou da vontade política dois países em desenvolvimento e constituiu o foro privilegiado onde seus interesses são postos à mesa das negociações globais (Gilberto C. Paranhos Velloso, “III UNCTAD: uma avaliação”, 14(13-18): 19-26, jan.-jun. 1972).

\section{Concepções do poder e desenvolvimento tecnológico}

As preocupações da diplomacia brasileira com a natureza, a distribuição e o exercício do poder avivaram-se com os escritos de Araújo Castro. O culto do poder, a insidiosa ideologia embutida na teoria realista dos norte-americanos segundo a qual poder é dado de fato ante o qual cabe resignar-se, a disposição das grandes potências de utilizar instrumentos jurídicos quando não a ação para congelar o poder mundial, a substituição a que procederam do conceito de desarmamento pelo de controle de armamentos, o efeito dessa política no sentido de admitir e manter nações responsáveis e irresponsáveis em escala internacional, os riscos do uso do poder congelado para congelar a desigualdade econômica entre as nações, o desrespeito à filosofia original que presidiu à elaboração da Carta de São Francisco e a necessidade de reformar o estatuto da ONU são alguns pensamentos desenvolvidas por Araújo Castro nos anos sessenta e setenta que irão alimentar o patrimônio político brasileiro em torno de ingredientes vitais da política exterior. Escrevia em tom pessimista, nosso teórico do poder: "Uma filosofia baseada exclusivamente no Poder afirma-se agora por toda a parte e, o que é mais grave, nunca o Poder e a violência desfrutaram de grau tão alto de respeitabilidade, na medida em que novas teorias e doutrinas se enunciam para justificá-los... O culto do Poder e o temor reverencial à Força tornaram-se tão respeitáveis que agora inspiram alguns dos documentos básicos das relações entre os homens... como exemplo, o Tratado de Não Proliferação de Armas Nucleares.” (J. A. de Araújo Castro, "Fundamentos da paz internacional: balança de poder ou segurança coletiva”, 13(49-50):7-23, mar.-jun. 1970).

Exemplificando com o malogro dos norte-americanos no Vietnã, o coronel Meira Mattos estabelece um distinção que afirma delinear-se nas duas últimas décadas na concepção do poder. Este tende em parte a desvincular-se da exclusiva 
força militar para abranger, além dela, a capacidade de influir internacionalmente (“O poder militar e a política internacional”, 16(63-64): 63-80, $2^{\circ}$ Semestre 1973). Pode-se supor que essa evolução na concepção do poder tenha em parte determinado a disposição da diplomacia brasileiro de reivindicá-lo como condição para fazer valer externamente os objetivos ditados pela percepção dos interesses nacionais. Pode-se supor igualmente que tenha influído sobre a evolução da doutrina de segurança, que na década de setenta transitou da tradicional segurança coletiva ao abrigo da potência hegemônica da área, os Estados Unidos, e do TIAR, para o conceito de segurança nacional? Em artigo publicado em 1978, Clóvis Brigagão interpreta o sentido e os efeitos da denúncia em 1977 por parte do Brasil do Acordo de Assistência Militar celebrado com os Estados Unidos em 1952. Muito além da questão do respeito aos direitos humanos - o Governo dos Estados Unidos condicionou a ajuda militar a um relatório sobre o assunto - pretexto tomado pelo Governo brasileiro para a denúncia, esta fazia desaparecer a estrutura formal da cooperação militar entre os dois países, erigida em contexto de Guerra Fria. O que estava em jogo era a nova concepção de segurança e a nova política de segurança, ambas bloqueadas pela dependência vigente. Desde 1967, enorme esforço vinha sendo empreendido no sentido de modernizar o equipamento militar nacional, absorvendo tecnologias do setor produtivo civil. Nos anos setenta, os progressos alcançados pela indústria bélica nacional situaram-na em condições de competitividade global e tornou-se necessário estabelecer uma política de exportação de armas. As diferenças com os Estados Unidos provinham, por um lado, das restrições à transferência de tecnologias aplicadas e, por outro, da competição no mercado internacional de armas. Varrer esses obstáculos exigia a ruptura da dependência, tanto mais que o desenvolvimento dos meios de defesa, supunha-se, viria beneficiar o progresso tecnológico sistêmico da nação, constituindo-se a política nacional de segurança o substitutivo encontrado para suprir a economia nacional de tecnologias de ponta que as grandes potências se negavam a transferir (Clóvis Brigagão, “Cancelamento do Acordo”, 22(81-84): 103-109, 1978).

Nem por isso a ação diplomática brasileira desacelerou seu movimento sobre o mercado internacional de tecnologias, muito pelo contrário. A importação de tecnologias por parte dos países em desenvolvimento estaria crescendo de forma exponencial, seus fluxos, custos e regulações estariam condicionando o processo de desenvolvimento. Daí porque, segundo Álvaro Gurgel de Alencar, teria o Brasil se tornado talvez o país do mundo com maior preocupação e mais intensa ação nessa esfera, nos órgãos multilaterais, com os objetivos de: a) melhorar os fluxos do comércio de tecnologias; b) levantar as restrições impostas pelos países avançados às transferências que afetassem interesses unilaterais e tornar assim o mercado internacional mais competitivo, com o conseqüente influxo sobre os preços (“Transferência de tecnologia”, 16(35-40): 63-80, 2 Semestre 1973). 
O início dos anos oitenta pode ser caracterizado por dois fenômenos que afetam a evolução dos conceitos que informam a conduta da diplomacia brasileira. Por um lado, considerar-se-ia encerrada a montagem do arcabouço teórico que vinha desde os anos sessenta, senão antes, desde Vargas e Kubitschek, sendo utilizado na construção do paradigma de política exterior desenvolvimentista. Nesse sentido, os anos oitenta não acrescem elementos importantes de criatividade mental. Por outro lado, observa-se clara mudança de percepção da ordem internacional e das possibilidades de ganhos externos para o desenvolvimento. Transita-se nos anos setenta do otimismo ao realismo, para aterrizar em crescente pessimismo que irá caracterizar particularmente o discurso diplomático nos anos oitenta. Não se arreda pé do paradigma de política exterior desenvolvimentista, cuja eficiência, entretanto, vai perdendo credibilidade. São todavia os obstáculos externos apontados como os responsáveis mais diretos pelos males da "década perdida". Dois textos introduzem em 1980 a inflexão pessimista do pensamento diplomático brasileiro: o chanceler Ramiro Saraiva Guerreiro analisa o impacto de uma conjuntura internacional adversa ao desempenho positivo da ação externa ("Visão da conjuntura e o comportamento diplomático do Brasil”, 23(89-92): 29-46, 1980); Roberto Abdenur e Ronaldo Sardenberg apontam o malogro geral do diálogo nortesul vis-à-vis das expectativas criadas e dos esforços empreendidos pelos países em desenvolvimento ("Notas sobre as relações norte-sul e o relatório Brandt", 23(89-92): 67-100, 1980).

\section{Estados Unidos, Argentina, Ocidente...: universalismo com parcerias estratégicas}

O pragmatismo do paradigma desenvolvimentista avançou, todavia, nos anos oitenta, uma estratégia de diversificação de parcerias como forma alternativa de superação de dificuldades. A Revista apreende e apóia a inovação, colocandose aliás à frente dos próprios acontecimentos. Assim é que, em número temático, estimula o entendimento entre o Brasil e a Argentina, afetado pelo contencioso em torno do aproveitamento dos recursos hídricos da Bacia do Prata, e, profeticamente, propõe a abertura de um ciclo de cooperação bilateral intensa, como ponto de partida para dinamização das relações regionais (Especial: "BrasilArgentina”, 24(93-96), 1981).

A idéia histórica de uma parceria útil a manter e desenvolver nas relações com os Estados Unidos é confrontada com a realidade do desentendimento existente em 1982. Três artigos retratam o pessimismo das percepções de lado a lado: para Henry Kissinger, diante do coro terceiro mundista como que comandado pelo maestro Brasil, “... se torna impossível pedir-nos que nos envolvamos em um diálogo construtivo...” ("Relações internacionais na década de 80”, 25(97-99): 91-99, 1982); para Hélio Jaguaribe, as visões de mundo, distintas e contraditórias, 
estariam afetando a cooperação bilateral (“Amigos, amigos, interesses à parte”, 25(97-100): 91-99, 1982). "As relações oficiais entre os dois países — avalia Albert Fishlow — não são boas nem más. Elas estão em grande parte perdidas”. O economista norte-americano propõe ao Governo Reagan mais atenção ao Brasil, como meio de superação do desencontro ("Relações Brasil-Estados Unidos: como evitar o desencontro”, 25(105-107): 91-99, 1982). Colocando-se sob outro prisma, a partir do crescimento alcançado e do potencial do Brasil, outro analista norteamericano, Wayne S. Selcher, embora apontando limites e fazendo sugestões corretivas, procede a uma avaliação otimista de seu peso relativo no cenário internacional. Esse autor não critica formalmente o parâmetro desenvolvimentista da política exterior brasileira, ao contrário, a partir de resultados positivos que descreve, indiretamente realça seu valor (“O Brasil e o mundo”, 26(101-104): 8390, 1983).

Desde o imediato pós-guerra e ao longo da segunda metade do século $\mathrm{XX}$, uma forte corrente de opinião, por vezes mais subterrânea por vezes mais aparente, reivindicava para o Brasil uma política exterior de caráter exclusivista em termos de opções estratégicas, porquanto deveria o país estreitar seus vínculos com o Ocidente e distanciar-se do Terceiro Mundo, promover uma inserção internacional associada econômica, ideológica e politicamente às matrizes do sistema capitalista.

O curso das relações internacionais do Brasil seria entretanto comandado pela opção estratégica universalista e autônoma, devendo porém esta justificar-se diante da opinião pública, sobretudo em épocas de crise. Em 1983, o Chanceler Saraiva Guerreiro expunha diante da Comissão de Relações Exteriores do Senado os argumentos em favor do universalismo brasileiro, rebatendo críticas que pretendiam forçar uma opção entre Ocidente e Terceiro Mundo. Sua tese é de que a complexidade ou pluralidade das dimensões brasileiras impõe ao país uma política exterior sem exclusões, caso deva ela atender a necessidades tão complexas: "Somos latino-americanos, mas, no continente, somos ao mesmo tempo platinos e amazônicos; somos um país atlântico, mas compartilhamos de longas e variadas fronteiras terrestres; temos forte e admirável contribuição africana na composição da nacionalidade ao lado de presença cultural, política e econômica ocidental fundamental para a compreensão da história brasileira. Somos um país de grandes potencialidades, mas também de diferentes necessidades que se agravam em instantes de crise”. As opões, pois, pelo Ocidente ou pelo Terceiro Mundo não são excludentes nas determinações de origem da diplomacia brasileira. "A definição de Ocidente é controvertida. Alguns a limitam à dimensão estratégica ou a um alinhamento político pretensamente rígido, empobrecendo-lhe o significado e as implicações. Para nós, brasileiros, penso que a compreensão do Ocidente deriva sobretudo da prevalência de valores, como os da democracia, dos direitos humanos, liberdade individual, tolerância, pluralismo, possibilidade de progresso e igualdade 
de oportunidades”. A inspiração política que flui dessas percepções e que norteia o conjunto das decisões na área externa não se choca, ao contrário, se soma a outras percepções, também evidentes na realidade nacional: "Nossa realidade, nossas condições sociais e econômicas, são flagrantemente de país em desenvolvimento... São importantes as implicações de condição de país em desenvolvimento, do Terceiro Mundo. Em primeiro lugar, ela envolve um modo próprio de encarar o sistema internacional.... Em segundo lugar encontramos várias coincidências naturais com posições negociadora de países em condições similares às nossas”. Duas idéias, em suma, alimentam o pensamento diplomático diante das opções estratégicas: uma sociedade plural requer uma política exterior universalista; o universalismo brasileiro descarta opções não só exclusivistas mas também opções confrontacionistas, razão porque a política exterior não adere à rígida confrontação ideológica da Guerra Fria como não segue os grupos que no Terceiro Mundo se organizam e atuam de forma a confrontar o Ocidente (Saraiva Guerreiro, “Ocidente e Terceiro Mundo”, 26(101-104): 147-162, 1983).

\section{Última defesa do paradigma desenvolvimentista e revisões conceituais}

No contexto da campanha eleitoral para a Presidência da República, a Comissão de Relações Exteriores da Câmara dos Deputados ouviu em novembro de 1984 Tancredo Neves, Celso Lafer, Marcílio Moreira e Hélio Jaguaribe. Embora cada um dos conferencistas tivesse preocupações próprias decorrentes das funções a exercer - o presumível chefe do Executivo, o jurista internacional, o economista e o cientista político - a transição para o regime civil não indicava uma inflexão conceitual da política exterior, cujo paradigma desenvolvimentista e pluralista haveria de se prolongar ("Exposições na Comissão de Relações Exteriores da Câmara dos Deputados”, 28(109-110): 149-188, 1985). Com efeito, ao tomar posse a 15 de março de 1985, o novo Chanceler Olavo Setúbal, embora valorizando seu caráter pragmático, fazia uma apologia da continuidade conceitual e estratégica da política exterior: "De fato, à medida que a tradição é a transmissão de valores espirituais através do tempo, cada Ministro compartilha com os que o antecederam do patrimônio comum da diplomacia brasileira. Na definição de sua agenda de problemas e seu estilo de ação, como reconheceu San Tiago Dantas, ele atualiza esse patrimônio com senso de oportunidade e em função das necessidades correntes sem, no entanto, perder a memória de suas origens. Todo novo Ministro desempenha, assim, o papel de intérprete e servidor dessa tradição" ("Discurso do Ministro Olavo Setúbal”, 28(111-112): 141-147, 1985).

Com a morte prematura de Tancredo Neves e a ascensão de José Sarney à Presidência em 1985, a equipe dirigente reforça conceitos forjados na tradição e ensaia sua adaptação aos desafios conjunturais. Assim, no entender do assessor especial do Presidente, Embaixador Rubens Ricupero, a política exterior do Brasil 
na virada do século prosseguiria voltada para questões econômicas. Dessa natureza tradicionalmente econômica da diplomacia, porém adaptada à evolução das forças que compunham o sistema internacional, derivavam seus princípios: a) abstenção em relação à política de poder; b) contribuição à superação do antagonismo lesteoeste e de toda polarização excessiva; c) consolidação da zona de paz no Atlântico Sul, com desnuclearização e desmilitarização; d) acentuação do universalismo conceitual e prático, com estabelecimento de relações multidirigidas para compensar a perda relativa de peso das relações com os Estados Unidos; e) integração da América Latina e f) abertura da economia brasileira e maior envolvimento do país com o comércio internacional ("O Brasil e o Mundo no século XXI”, 29(115-116): 5-20, 1986).

Prevalecia nos anos oitenta a interpretação segundo a qual os conflitos de interesses e os desentendimentos com os Estados Unidos estariam forçando a diplomacia brasileira a acentuar traços compensatórios para a tradicional relação especial, consoante os estudos sobre essa "rivalidade emergente" do historiador Moniz Bandeira: “A expansão econômica do Brasil, portanto, superou as contingências que o levaram, durante alguns períodos, a um alinhamento automático com os Estados Unidos. Criaram-se as condições para uma política de crescimento não-condicionado, sem subordinação a outras lideranças, levando o país à competição por sua própria área e à participação, com voz ativa, na estrutura mundial de poder... Assim, os atritos com os Estados Unidos, ainda dominantes, tornam-se inevitáveis, e não só por motivos ideológicos. O Brasil, como potência emergente, age em defesa dos seus interesses nacionais” "“Continuidade e mudança na política externa brasileira”, 29(115-116): 91-98, 1986).

Com a assinatura em 1986 de protocolos que representavam uma inovação quanto ao processo de integração da América Latina, a partir do eixo Brasil-Argentina, a noção de integração adquire novo significado na conceituação diplomática. Hélio Jaguaribe resume esse novo estádio de evolução: a) expansão do comércio bilateral; b) desenvolvimento da capacitação tecnológica mediante a conjugação de esforços; c) integração desenvolvimentista das unidades econômicas nacionais em projetos de grande relevância; d) elevação da capacidade de negociação internacional dos parceiros (“A integração Argentina-Brasil”, 30(117118): 39-56, 1987). Os elementos b e c desse conceito de integração seriam abandonados pelos governos liberais dos anos noventa, mas os outros dois se manteriam norteando as decisões do processo de integração que tomaria feições já consolidadas com o MERCOSUL.

Outro domínio conceitual que passa por redefinição nos anos oitenta é o do desenvolvimento científico e tecnológico. Como o desenvolvimento industrial do Brasil conduziu à apropriação de tecnologias de livre acesso, as tecnologias intermediárias, a apropriação de tecnologias sensíveis e de ponta foi tradicionalmente procurada por empreendimentos estatais por meio da pesquisa 
própria e da cooperação internacional. O Embaixador Oscar Lorenzo Fernandes supunha em 1988 que era chegado o momento de o Brasil envolver a iniciativa privada nacional e a cooperação com empresas privadas estrangeiras, em condições de respeito às normas de propriedade intelectual e patentes, para alcançar condições de inovação que caracterizam economias de desenvolvimento avançado ("O desenvolvimento tecnológico do Brasil e a cooperação internacional”, 31(123124): 29-39, 1998). Celso Amorim, por sua vez, complementa essa nova conceituação da política de desenvolvimento tecnológico: a) a cooperação internacional não é alternativa, porém complemento do esforço interno; b) só será frutífera quando houver interesses compartidos, o que supõe níveis simétricos de desenvolvimento entre as partes; c) o Brasil deve passar por ajustes no aparato institucional para criar condições de inovação, ou seja, para converter ciência em tecnologia; d) o esforço primordial não é o da cooperação, mas o da geração interna de conhecimentos e tecnologias ("Perspectivas da cooperação internacional", 31(123-124): 49-58, 1988).

\section{Rumo ao novo paradigma liberal dos anos noventa}

A Revista comprova a revisão de conceitos em curso nos anos oitenta, sem que o paradigma desenvolvimentista das últimas décadas fosse afetado. Paulo Tarso Flecha de Lima, por exemplo, em texto de 1988, elabora um diagnóstico de certas distorções que a longevidade do paradigma desenvolvimentista provocou: demasiado protecionismo, baixo nível de inserção econômica internacional, tabus terceiro-mundistas que inibem a capacidade de negociação internacional. Advogava, como que, a passagem para o Brasil da fase de nacionalização da economia internacional para a de internacionalização da economia nacional ("Modernização e obstáculos para a internacionalização da economia brasileira”, 31(123-124): 103-106, 1988).

O mesmo Flecha de Lima é um dos primeiros diplomatas a vir a público para argumentar em favor do novo ideário neoliberal em curso com a ascensão à Presidência de Fernando Collor em 1990. Observa o declínio global do poder do Estado com a uniformização ideológica que sucedeu ao fim da Guerra Fria em torno do liberalismo, a conversão do keynesianismo em neoliberalismo das políticas econômicas dos países desenvolvidos, as transformações políticas e econômicas do Leste Europeu e a nova face da Europa como um todo, a formação de megablocos econômicos e as novas idéias e regulações empreendidas no seio da Rodada do Uruguai do GATT, os novos temas em discussão, como os direitos humanos, o meio ambiente e a propriedade intelectual. “... o Brasil não pode alhear-se a esse movimento, a essas novas exigências. Fazê-lo seria virar as costas para a interação com o mundo, manter-se recluso, infenso à modernidade”, concluía o Embaixador, que delineava o pensamento da adaptação aos desafios da liberalização como 
substitutivo do ideário histórico do desenvolvimento autocentrado (“O Brasil no panorama internacional: desafios e controvérsias”, 33(129-130): 9-32, 1990). Em outros termos, argumenta-se pelo fim de uma política exterior de objetivos definidos autonomamente, na linha de pensamento do paradigma desenvolvimentista, em favor de uma adaptação reativa às mudanças e condições criadas externamente pela onda liberalizante que contagiou o mundo nos anos noventa.

Os pensadores liberais em voga nos anos noventa pretendem substituir uma densa e sólida filosofia política acumulada em décadas de pensar e fazer política exterior, mas são sóbrios, esquivos e muito breves quando se trata de fundamentar suas doutrinas e desenvolver seus conceitos. O discurso diplomático torna-se podre, aliás calado. Ocasiões antes utilizadas como momentos privilegiados de manifestá-lo são desprezadas. Mesmo notáveis intelectuais e pensadores, como os Chanceleres Francisco Rezek e Celso Lafer, tiram o brilho de cerimônias com seu silêncio ou com suas evasivas expressões, de que constitui exemplo o discurso de posse deste último: "O liberalismo de inovação, ao qual eu me filio, reconhece a importância de uma constante busca de eficiência que o mercado instiga, afirma a liberdade nos planos político e pessoal, e exige o respeito ao primado da legalidade, inerente ao estado de direito" ("Discurso do professor Celso Lafer na cerimônia de transmissão do cargo de Ministro de Estado das Relações Exteriores”, 35(137-138): 89-92, 1992).

A evolução conceitual dos anos noventa fundava-se em diagnóstico das distorções que vinham sendo apontados no modelo de desenvolvimento nacional e acelerava-se por pressão das mutações em curso na ordem internacional. Os anos noventa puseram, pois, ao Brasil o desafio de adaptar-se, uma necessidade quase consensual entre diplomatas, políticos, intelectuais e lideranças empresariais. Contudo, este consenso desfazia-se com o avançar de uma filosofia política neoliberal adotada de forma quase dogmática pelos governos de Fernando Collor e Fernando Henrique Cardoso, com reações de parcelas da opinião em todos os meios e de segmentos organizados da sociedade, capazes enfim de projetar em parte suas idéias e a percepção de suas necessidades para o domínio do processo decisório, tanto em termos de políticas públicas internas quanto de política exterior. Sem ameaçar-lhes a essência neoliberal.

Abril de 1998

\section{Resumo}

A evolução dos conceitos imanentes à política exterior do Brasil é descrita com base nos textos da Revista Brasileira de Política Internacional, fundada em 1958. Sucedendo ao universalismo e ao regionalismo aventados ao final dos anos 
cinqüenta, a década seguinte é marcada pela radicalização das correntes de pensamento que se filiam seja a uma concepção autonomista introvertida seja a uma concepção associada e aberta do desenvolvimento. A primeira corrente aprimora seus conceitos e prevalece como fundamento da política exterior durante as décadas de setenta e oitenta. A segunda é retomada em 1990 em razão de distorções percebidas na condução do paradigma desenvolvimentista e por pressões externas de uma nova ordem internacional.

\section{Abstract}

The evolution of the main concepts of the Brazilian foreign policy is seen through the articles published in the Revista Brasileira de Política Internacional, established in 1958. Coming after the "universalism" and the "regionalism" proclaimed at the end of the 50s, the next decade shows the radicalization of political currents of thought, adhering either to an autonomous and autarchical national project either to a liberal conception, foreign-friendly, of development. The first one sharpen its concepts and prevails as a solid ground for the foreign policy during the 70s and 80s. The second arises again in 1990, emerging from the distortions perceived in the implemention of "developmentalist” paradigm and from external pressures coming from the new international order.

Palavras-chave: Brasil: pensamento diplomático, história.

Key-words: Brazil: diplomatic thought, history. 